\title{
Treating White Leaf Disease in Sugarcane Cuttings Using Solution Plasma
}

\author{
Janjira Sroykaew ${ }^{1}$, Komgrit Leksakul ${ }^{1 *}$, \\ Dheerawan Boonyawan ${ }^{2}$ and Angsana Akarapisan ${ }^{3}$ \\ ${ }^{1}$ Faculty of Engineering, Chiang Mai University, Chiang Mai 50200, Thailand \\ ${ }^{2}$ Faculty of Science, Chiang Mai University, Chiang Mai 50200, Thailand \\ ${ }^{3}$ Faculty of Agriculture, Chiang Mai University, Chiang Mai 50200, Thailand \\ *Corresponding author.E-mail: komgrit@eng.cmu.ac.th \\ https://doi.org.10.12982/CMUJNS.2018.0006
}

\begin{abstract}
Sugarcane, an important agricultural crop, is susceptible to white leaf disease, which can severely damage the crop and income. The disease is caused by phytoplasma, a prokaryote in the class mollicutes. This study investigated the efficacy of treating the disease by sterilization with solution plasma technology, including wire-to-wire, plasma jet, and gliding arc systems. Nested PCR and a scanning electron microscope were used to examine the phytoplasma disease and evaluate the effectiveness of the various solution plasma treatments. The most effective treatments, in terms of balancing plant growth and disease reduction, were the wire-to-wire system, with infected specimens immersed during discharge for 2 min with discharge repeated every 2 min, for 120 min (Exp 13); and the plasma jet system, with infected specimens immersed during discharge for 30 min and then continuously immersed for $180 \mathrm{~min}$ (Exp 18). The wire-to-wire treatment yielded $50 \%$ disease-free sugarcane specimens with $80 \%$ growth; the plasma jet system yielded fewer disease-free sugarcane specimens (40\%), but more growth (90\%). Additionally, SEM results showed that the solution plasma treatments as a group reduced disease incidence by about one third compared to the controls.
\end{abstract}

Keywords: White leaf disease, Sugarcane, Phytoplasma, Solution plasma

\section{INTRODUCTION}

Sugarcane, an important agricultural crop, is susceptible to white leaf disease, which can severely damage the crop and income. White leaf disease in sugarcane is caused by phytoplasma parasites that destroy the plant's chlorophyll, which is responsible for photosynthesis and the green color of the leaves. Phytoplasma are bacterial parasites classified as prokaryotes of the mollicutes class (Pagliari et al., 2016). They have no cell wall and are of an uncertain shape of 400-900 $\mathrm{nm}$. They live in the sieve tubes of the sugarcane, scattering to all parts of the plant. White leaf disease cannot be cultured in synthetic food (Om-Hashem et al., 2015). 
Plasma technology, a newly developed sterilization process, may offer potential for treating this disease in sugarcane, particularly solution plasma, a liquid phase discharge, that can be produced at room temperature and normal atmospheric pressure. It offers technological promise, especially as applied to sterilization, as it contains free radicals, such as the hydroxyl free radical $(\mathrm{OH} \bullet)$, a very strong and hypersensitive oxidizing agent (Prasertsung et al., 2013). Due to these properties, $\mathrm{OH} \bullet$ in solution plasma can destroy the structure of cell walls and elements within cells, eventually killing the cells. After the process ends, $\mathrm{OH} \bullet$ and other free radicals try to reduce their energy and return to steady state. At steady state, the residual solution plasma is safe and environmentally friendly (Kim et al., 2013).

Three systems for generating solution plasma have shown potential as sterilization technologies: the wire-to-wire electrode, plasma jet, and gliding arc systems. Andreeva et al. (2012) reported that solution plasma has the potential to rapidly sterilize water without chemical agents, and performed well against Escherichia coli bacteria.

In the wire-to-wire electrode system, the electrode is immersed in the solution and a high energy and high frequency electric current is passed from one side of the electrode to the other. This causes the molecules in the solution to vibrate and split into electrons, ions, and atoms. With continuous application of electric current, the electrons, ions, and atoms gain energy and move randomly, with their collisions generating plasma. Although this technique dissolves the plasma well in the solution, it requires considerable energy because of the solution's high resistance.

The plasma jet system is a single electrode, non-thermal system under atmospheric pressure capable of directing the flow of plasma. A copper foil electrode is connected to a high-voltage source. Pure argon or premixed argon and oxygen is used as the working gas. As the gas flows through the electrode, its velocity dramatically increases. As the high-energy gas atoms collide with the solution or water's surface, it generates plasma, creating reactive oxygen species, including $\mathrm{OH} \bullet$ (Chingsungnun et al., 2016). Ma et al. (2015) reported on the potential of plasma-activated water generated by a plasma jet to inactivate Staphylococcus aureus (S. aureus) inoculated on strawberries.

El-Aragi (2005) developed the gliding arc system. It is similar to the plasma jet system, except the electrode is shaped into a curve or other forms, rather than an endpoint. Because the various electrode shapes provide greater surface contact, the directed gas flow has higher energy.

This study tested and compared the effectiveness of these three plasma solution technologies for treating white leaf disease in sugarcane. In addition, we used nested PCR technique to investigate the phytoplasma that causes white leaf disease.

\section{MATERIALS AND METHODS}

\section{Sugarcane specimen preparation}

This study used 7-10 month-old sugarcane of the U Thong 12 variety. Samples with white leaf disease were selected by observing their symptoms, and confirmed by nested PCR technique. The sugarcane samples were cleaned with a half dry towel, and then cut (approximately $1.5 \mathrm{~cm}$ from the joints) into pieces that included one bud. 


\section{Disease detection by nested PCR}

White leaf disease in the samples was confirmed by nested PCR technique. DNA was extracted from the sugarcane buds by adapting the outcrossing rates/ microsat method of Kalisz (2016). To detect the disease, we followed the method of Hanbunsong et al. (2005) and Klingkong (2015) exactly, using two sets of specific primers 1) MLO-X:5-GTTAGGTTAAGTCCTAAAACGAGC-3 and MLO-Y:5-GTGCC AAGGCATCCACTGTATGCC-3 and 2) P1:5-GTCGTAACAAGGTATCCCTACC GG-3 and P2:5-GGTGGGCCTAAATGGACTTGAACC-3 mixed with different master solutions to extract the DNA of the phytoplasma. The presence of the 210 base pair amplified DNA fragments of phytoplasma used to confirm white leaf disease in the samples (Figure 1).

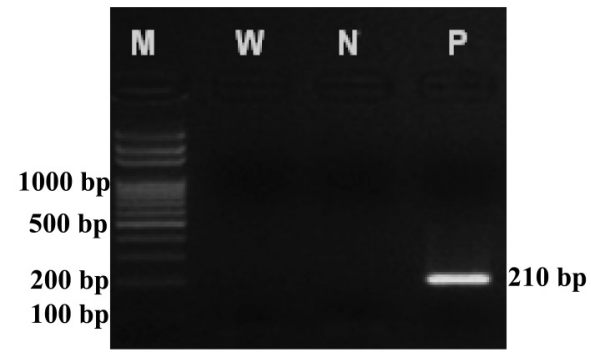

Figure 1. An example showing confirmation of white leaf disease in a sugarcane sample by detecting the 210 base pair amplified DNA fragment of phytoplasma.

Note: Column N shows the bands of standard DNA, column W is double distilled water, column N is healthy sugarcane, and column $\mathrm{P}$ is sugarcane with white leaf disease.

\section{Control treatments}

Five control treatments were tested and later compared with samples subjected to the three experimental plasma treatments:

- Infected specimens were untreated (Control 1).

- Infected specimens were immersed in tetracycline solution with $200 \mathrm{mg} / \mathrm{l}$ at room temperature for 3 days (Control 2).

- Infected specimens were immersed in hot water at $50^{\circ} \mathrm{C}$ for $120 \mathrm{~min}$ (Control 3).

- Infected specimens were immersed in sodium sulfate solution at room temperature for $120 \mathrm{~min}$ (Control 4).

- Infected specimens were immersed in sodium sulfate solution at $50^{\circ} \mathrm{C}$ for $120 \mathrm{~min}$ (Control 5).

\section{Wire-to-wire electrode system}

In this system, increasing the solution concentration leads to higher electric conductivity and plasma density. To identify the optimal concentration that would destroy the phytoplasma, but not the host sugarcane, we generated plasma solution at $500 \mathrm{~V}$ using different solution concentrations. The infected specimens were then immersed in the solution at room temperature for $120 \mathrm{~min}$. After sterilization, the specimens were planted in sterilized soil and growth recorded; the most appropriate concentration of sodium sulfate was then selected. 
The most appropriate concentration of sodium sulfate solution was prepared in an acrylic reactor. A tungsten cathode ( $1 \mathrm{~mm}$ in diameter) and anode were placed in the solution 3 $\mathrm{mm}$ apart. The wire-to-wire electrode was connected with an IDP 1010s intelligent DC power supply. When the system produced plasma with high-density free radicals, three different groups of experiments were conducted:

- Infected specimens were immersed during the discharge for 1 or $2 \min$ (EXP 1 and EXP2, respectively).

- The solution was discharged for 2 min. After discharge, infected specimens were immersed for 5, 10, 15, 30, 60, 120, 180, 240, 300, or 360 min (EXP 3-12, respectively).

- Infected specimens were immersed during the discharge for 2 min and discharge was repeated every 2, 10, or $20 \mathrm{~min}$, for $120 \mathrm{~min}$ (EXP 13-15, respectively).

\section{Plasma jet system}

The plasma jet system used $30 \mathrm{ml}$ of deionized water. The plasma jet head was connected to a high-voltage, radio frequency (RF) power supply $(80-800 \mathrm{MHz}, 100 \mathrm{~W})$ that was placed on the surface of the water. The following were set: power $30 \mathrm{~W}$, argon gas flow rate $5 \mathrm{l} / \mathrm{min}$, and oxygen gas flow rate $20 \mathrm{l} / \mathrm{min}$. Infected specimens were immersed while discharged for $30 \mathrm{~min}$ and then continuously immersed for $0,30,180$, or $300 \mathrm{~min}$ (EXP 16-19, respectively).

\section{Gliding arc system}

The gliding arc system used a $125-\mathrm{W}, 8-\mathrm{kV}$ DC power supply, with voltage set at 8 $\mathrm{kV}$, and argon gas flow rate of $15 \mathrm{ml} / \mathrm{min}$ and water flow rate of $20 \mathrm{ml} / \mathrm{min}$. Each infected specimen needed at least $30 \mathrm{ml}$ of plasma solution. After generating enough activated solution (approximately $1.5 \mathrm{~min}$ ), the infected specimens were immersed in the activated solution for 240, 480 or $720 \mathrm{~min}$ (EXP 20-22, respectively).

\section{Growing the sugarcane}

After all control and experimental treatments, the sugarcane samples were planted and their growth compared by $\%$ growth and $\%$ disease-free survival. All samples were grown in sterilized soil prepared in pots $(7 \mathrm{~cm}$ diameter). The pots were moved into a bright and airy building with protective insect nets. Growth was tracked for 30 days. The sugarcane leaflets were tested for phytoplasma using nested PCR technique as before. A JSM 5910 LV-scanning electron microscope was used to confirm the presence of the disease in those samples that tested positive using nested PCR. Five samples were tested from each leaf specimen: two that were randomly selected from the head and tail of the leaf edges and three that were randomly selected from the leaf center. 


\section{RESULTS}

\section{Appropriate sodium sulfate concentration}

The growth of the uninfected sugarcane samples at various sodium sulfate concentrations is shown in Figure 2. Increasing the concentration decreased growth. However, low concentrations did not produce enough high-density plasma for sterilization. We selected 10 $\mathrm{g} / \mathrm{l}$ as most appropriate, as growth matched the control (Figure 2), and this was the minimum concentration that yielded the $\mathrm{OH}$ free radical (Table 1). The summary of this concentration is shown in Figure 3.

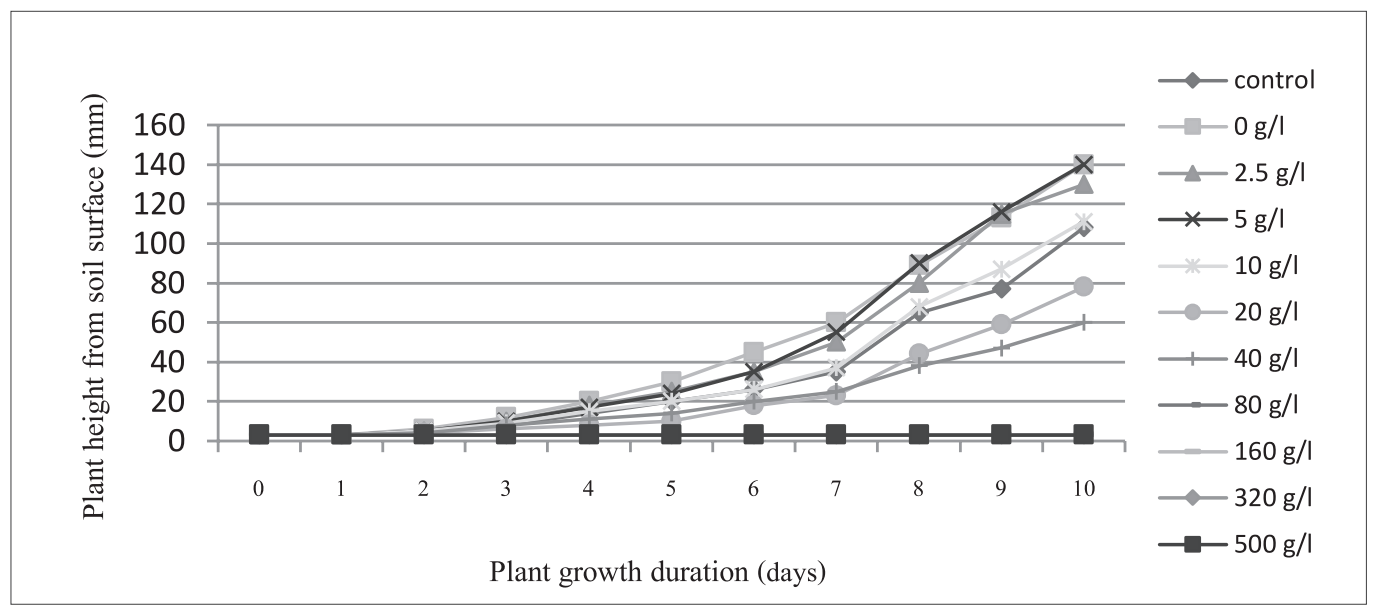

Figure 2. Growth of uninfected sugarcane samples.

Table 1. Substances detected by OES.

\begin{tabular}{lcccccc}
\hline \multirow{2}{*}{$\begin{array}{l}\text { Substances detected } \\
\text { by OES }\end{array}$} & $\mathbf{0 . 0}$ & $\mathbf{2 . 5}$ & $\mathbf{5 . 0}$ & $\mathbf{1 0 . 0}$ & $\mathbf{2 0 . 0}$ & $\mathbf{4 0 . 0}$ \\
\cline { 2 - 7 } $\mathrm{H}_{2}$ & - & + & + & + & + & + \\
$\mathrm{O}_{2}$ & - & + & + & + & + & + \\
$\mathrm{Na}$ & - & + & + & + & + & + \\
Free OH radical & - & - & - & + & + & - \\
\hline
\end{tabular}

Note: + detected, - not detected. 


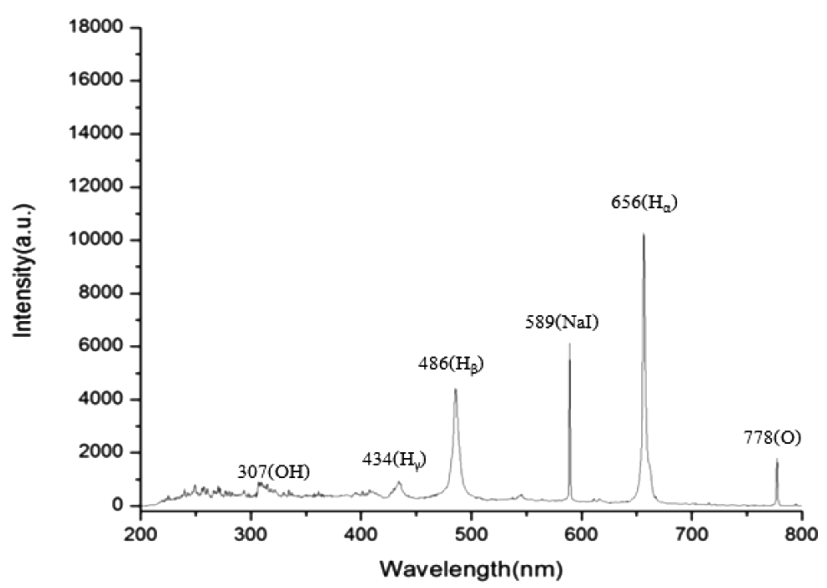

Figure 3. The different substances and their amounts measured by OES from the wire-towire electrode system using sodium sulfate $10 \mathrm{~g} / 1$.

\section{Control test}

Table 2 shows the results of the five control treatments of the infected samples. Each test was replicated four times. Nested PCR confirmed all control samples were infected. Control 2 (tetracycline solution) inhibited all growth, indicating that this traditional treatment destroyed the plant itself.

Table 2. The results of the control treatments.

\begin{tabular}{lcccccc}
\hline & \multicolumn{6}{c}{ Results } \\
\cline { 2 - 7 } Experiment & \multicolumn{2}{c}{ \% Growth } & \multicolumn{4}{c}{ \% Disease-free } \\
\cline { 2 - 7 } & \multicolumn{7}{c}{$\begin{array}{c}\text { Tested } \\
\text { by observation }\end{array}$} & \multicolumn{2}{c}{ Tested } \\
& \multicolumn{1}{c}{$\mathbf{x}$} & S.D. & $\overline{\mathbf{x}}$ & S.D. & $\overline{\mathbf{x}}$ & S.D. \\
\cline { 2 - 7 } & 85.0 & 19.1 & 0.0 & 0.0 & 0.00 & 0.0 \\
\hline Control 1 & 0.0 & 0.0 & 0.0 & 0.0 & 0.00 & 0.0 \\
Control 2 & 60.0 & 23.1 & 30.0 & 34.6 & 0.00 & 0.0 \\
Control 3 & 85.0 & 19.1 & 0.0 & 0.0 & 0.00 & 0.0 \\
Control 4 & 60.0 & 23.1 & 30.0 & 11.5 & 0.00 & 0.0 \\
Control 5 & & & & & & \\
\hline
\end{tabular}

\section{Wire-to-wire electrode system}

Table 3 shows the results of experiments 1-12, in which all samples were treated by the wire-to-wire electrode system; this technique efficiently produced a high volume of active solution. EXP 1 and 2 (infected specimens were immersed during the discharge for 1 or $2 \mathrm{~min}$ ) were not effective treatments, as all samples remained infected. EXP 9 (solution discharged for $2 \mathrm{~min}$, infected specimens immersed for $180 \mathrm{~min}$ ) exhibited the highest \% growth. EXP 4 and 12 (solution discharged for $2 \mathrm{~min}$, infected specimens immersed for 10 and $360 \mathrm{~min}$, respectively) yielded the the highest \% disease-free, but EXP 12 grew the least. The 
optimal mix of \% growth and disease-free was EXP 4 (solution discharged for 2 min, infected specimens immersed for $10 \mathrm{~min}$ ). Figure 4 was constructed based on the data sets from Table 3 for EXP 3-12.

Table 3. The results of the wire-to-wire electrode system for EXP 1-12.

\begin{tabular}{|c|c|c|c|c|c|c|c|c|}
\hline \multicolumn{3}{|c|}{ Experiment } & \multicolumn{6}{|c|}{ Results } \\
\hline \multirow[t]{3}{*}{ No. } & \multirow[t]{3}{*}{$\begin{array}{c}\text { Discharge } \\
\text { (min) }\end{array}$} & \multirow{3}{*}{$\begin{array}{c}\text { Post- } \\
\text { discharge } \\
\text { (min) }\end{array}$} & \multicolumn{2}{|c|}{$\%$ Growth } & \multicolumn{4}{|c|}{$\%$ Disease-free } \\
\hline & & & & & \multicolumn{2}{|c|}{$\begin{array}{c}\text { Tested } \\
\text { by observation }\end{array}$} & \multicolumn{2}{|c|}{$\begin{array}{c}\text { Tested } \\
\text { by nested PCR }\end{array}$} \\
\hline & & & $\overline{\mathbf{x}}$ & S.D. & $\overline{\mathbf{x}}$ & S.D. & $\overline{\mathbf{x}}$ & S.D. \\
\hline 1 & 1 & - & 95.0 & 10.0 & 0.0 & 0.0 & 0.0 & 0.0 \\
\hline 2 & 2 & - & 95.0 & 10.0 & 0.0 & 0.0 & 0.0 & 0.0 \\
\hline 3 & 2 & 5 & 80.0 & 40.0 & 5.0 & 10.0 & 5.0 & 10.0 \\
\hline 4 & 2 & 10 & 90.0 & 20.0 & 15.0 & 30.0 & 15.0 & 30.0 \\
\hline 5 & 2 & 15 & 65.0 & 19.1 & 10.0 & 11.5 & 10.0 & 11.5 \\
\hline 6 & 2 & 30 & 70.0 & 20.0 & 10.0 & 11.5 & 10.0 & 11.5 \\
\hline 7 & 2 & 60 & 65.0 & 30.0 & 15.0 & 10.0 & 0.0 & 0.0 \\
\hline 8 & 2 & 120 & 90.0 & 20.0 & 25.0 & 10.0 & 10.0 & 20.0 \\
\hline 9 & 2 & 180 & 95.0 & 10.0 & 10.0 & 20.0 & 10.0 & 20.0 \\
\hline 10 & 2 & 240 & 75.0 & 30.0 & 10.0 & 11.5 & 10.0 & 11.5 \\
\hline 11 & 2 & 300 & 80.0 & 28.3 & 20.0 & 23.1 & 10.0 & 11.5 \\
\hline 12 & 2 & 360 & 60.0 & 28.3 & 20.0 & 16.3 & 15.0 & 10.0 \\
\hline
\end{tabular}

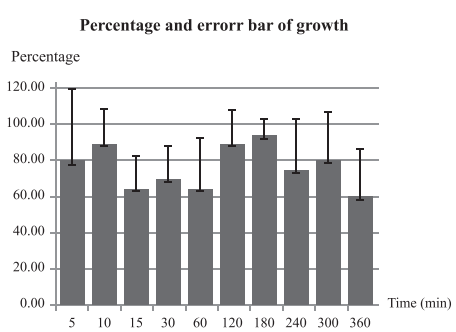

(A)

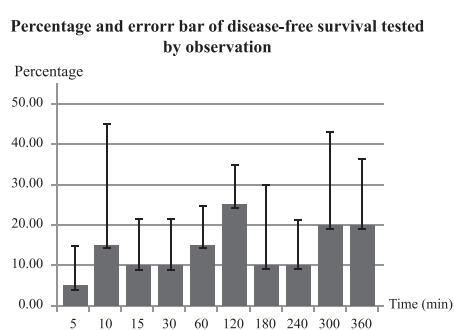

(B)

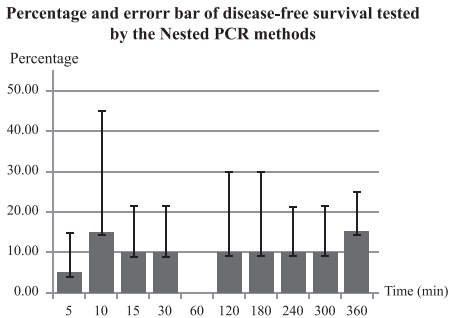

(C)

Figure 4. Percentage and error bar of growth (a) and disease-free by observation (b) and nested PCR (c) of EXP 3-12.

\section{Three different solution plasma systems}

Table 4 shows the results of EXP 13-22. Gliding arc technique (EXP 20) showed promising growth $(100 \%)$, but all samples remained infected ( $0 \%$ disease-free). Wire-to-wire (EXP 13) showed the highest disease-free percentage (50\%), with reasonable growth (80\%). Plasma jet (EXP 18) showed higher growth (90\%) than wire-to-wire, but lower disease-free rates $(40 \%)$. The data sets in Table 4 are plotted in Figure 5. 
Table 4. Results from the three different plasma solution systems.

\begin{tabular}{|c|c|c|c|c|c|c|c|c|c|}
\hline \multicolumn{4}{|c|}{ Experiment } & \multicolumn{6}{|c|}{ Results } \\
\hline \multirow[t]{3}{*}{ No. } & \multirow{3}{*}{$\begin{array}{l}\text { Wire- } \\
\text { to-Wire }\end{array}$} & \multirow{3}{*}{$\begin{array}{c}\text { Plasma } \\
\text { Jet }\end{array}$} & \multirow{3}{*}{$\begin{array}{l}\text { Gliding } \\
\text { arc }\end{array}$} & \multicolumn{2}{|c|}{$\%$ Growth } & \multicolumn{4}{|c|}{$\%$ Disease-free } \\
\hline & & & & \multirow[b]{2}{*}{$\overline{\mathbf{x}}$} & \multirow[b]{2}{*}{ S.D. } & \multicolumn{2}{|c|}{$\begin{array}{c}\text { Tested } \\
\text { by observation }\end{array}$} & \multicolumn{2}{|c|}{$\begin{array}{c}\text { Tested } \\
\text { by nested PCR }\end{array}$} \\
\hline & & & & & & $\overline{\mathbf{x}}$ & S.D. & $\overline{\mathbf{x}}$ & S.D. \\
\hline 13 & $\mathrm{x}$ & & & 80.0 & 0.0 & 60.0 & 0.0 & 50.0 & 14.0 \\
\hline 14 & $\mathrm{x}$ & & & 50.0 & 42.4 & 30.0 & 14.1 & 30.0 & 14.1 \\
\hline 15 & $\mathrm{x}$ & & & 0.0 & 0.0 & 0.0 & 0.0 & 0.0 & 0.0 \\
\hline 16 & & $\mathrm{x}$ & & 90.0 & 14.1 & 20.0 & 0.0 & 20.0 & 0.0 \\
\hline 17 & & $\mathrm{x}$ & & 80.0 & 0.0 & 20.0 & 0.0 & 10.0 & 14.0 \\
\hline 18 & & $\mathrm{x}$ & & 90.0 & 14.1 & 40.0 & 0.0 & 40.0 & 0.0 \\
\hline 19 & & $\mathrm{x}$ & & 20.0 & 28.3 & 0.0 & 0.0 & 0.0 & 0.0 \\
\hline 20 & & & $\mathrm{x}$ & 100.0 & 0.0 & 20.0 & 0.0 & 0.0 & 0.0 \\
\hline 21 & & & $\mathrm{x}$ & 60.0 & 0.0 & 10.0 & 14.1 & 0.0 & 0.0 \\
\hline 22 & & & $\mathrm{x}$ & 0.0 & 0.0 & 0.0 & 0.0 & 0.0 & 0.0 \\
\hline
\end{tabular}
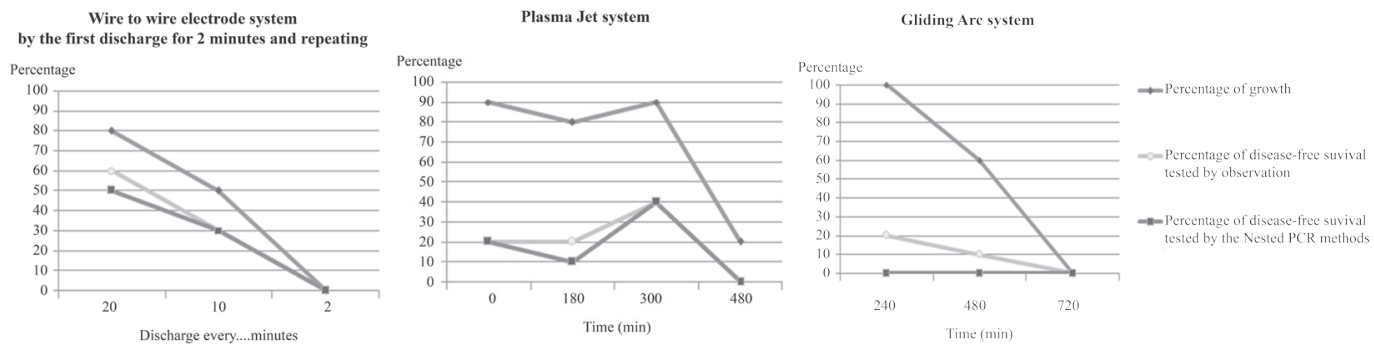

Figure 5. Percentage growth and disease-free results of the three different plasma solution systems.

Table 5 shows the \% disease detected, calculated as the infected area divided by the total area, as observed by SEM. This confirmed the nested PCR results. The SEM results showed that solution plasma was an effective treatment for white leaf disease in sugarcane, reducing disease incidence over the control from $8 \%$ to $5.3 \%$, or about one third. 
Table 5. The percent disease detected by SEM examination of the control and plasma-treated samples after growth.

\begin{tabular}{lc}
\hline Test & $\begin{array}{c}\text { Average } \% \\
\text { disease detected }\end{array}$ \\
\hline Healthy sugarcane (Control) & 0.00 \\
Uninfected sugarcane after treating with the solution plasma & 0.00 \\
Infected sugarcane (Control) & 8.00 \\
Infected sugarcane after treating with the solution plasma & 5.33 \\
\hline
\end{tabular}

\section{DISCUSSION}

Our study showed that the solution plasma treatments as a group reduced disease incidence by about one third compared to the controls. Depending on the solution plasma treatment, both the wire-to-wire and plasma jet systems reduced white leaf disease incidence, but they also reduced sugarcane growth to varying degrees. The free radicals in the plasma treatments affected both the sugarcane and phytoplasma. In terms of the sugarcane, Misra et al. (2016), using sucrose obtained from sugarcane juice, a carbohydrate that is a biomolecule formed by a glycosidic linkage (a type of covalent bond) that links one molecule of glucose and one molecule of fructose, showed that hydroxyl free radicals react with carbohydrates to damage the structure of the sucrose molecule. Misra et al. (2016), using cellulose from the cell wall of the apical meristem (bud and root primordia), which is a carbohydrate and biomolecule that is produced from glucose molecules linked together in a long chain by a hydrogen bond, also showed that hydroxyl free radicals react with the carbohydrate and damage the molecular structure of the cellulose.

The physical structure of phytoplasma, three trilaminar membranes, is a similar morphology to microplasma (Junplang, 2012). According to Roberston's (2017) model of a trilaminar membrane structure (Figure 6), the plasma membrane surface has a glycoprotein coat; this is a complex substance produced by the covalent bond between a carbohydrate molecule and protein (Misra et al., 2016). The free radicals in the plasma solution damage this plasma membrane of phytoplasma, leading to severe cell damage and death.

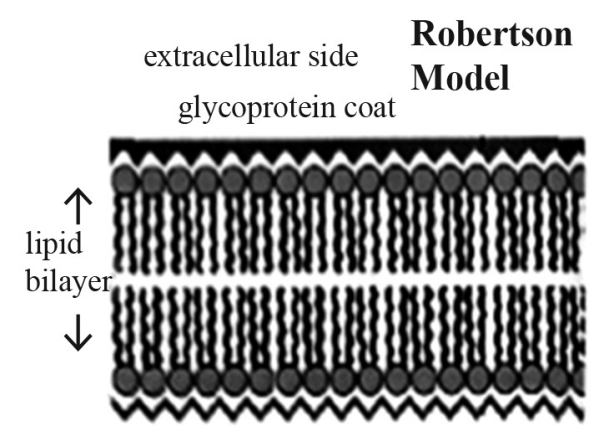

Figure 6. Trilaminar membrane structure.

Note: https://www.slideshare.net/raiuniversity/bsc-micro-ii-microbial-physiology-unit-3-bacterialpermeation, February, 2017) 
The phytoplasma that cause white leaf disease in sugarcane live inside the phloem cells. To try to eliminate the parasite, the infected sugarcane specimens were immersed in solution plasma that consisted of ions, electrodes, and free radicals. These solution substances spread into the sugarcane cells through the phloem, where they first cause an oxidation reaction with the sugarcane itself - the glucose molecules in the sugarcane juice and the cellulose in the cell walls of the apical meristem. This both damages the plant, affecting its growth, and reduces the number of free radicals available to attack the phytoplasma. In infected sugarcane specimens showing signs of white leaf disease, it is possible that the hydroxyl free radicals remaining after reacting with the sugarcane were insufficient compared to the amount of phytoplasma in the plant's phloem, and white leaf disease remained.

In some of the sugarcane specimens where the visually observable symptom of white leaves had been eliminated, nested PCR technique still detected the disease. The solution plasma with its hydroxyl free radicals reduced the disease, but was not able to eliminate it. In other specimens, nested PCR found no remaining disease; perhaps the initial infection was low enough that the hydroxyl free radicals in the solution plasma reacted with the phytoplasma in the phloem directly, and caused little damage to the sugarcane tissue, allowing it to grow disease-free.

In the sugarcane specimens that did not grow after exposure to the solution plasma a possible cause was the high concentration of hydroxyl free radicals reacting with the apical meristem in the buds and roots; critical parts for plant growth. The rough pits in the phloem walls seen with scanning electron microscope (10,000 times magnification) after exposure to the solution plasma treatment show the tissue damage it causes.

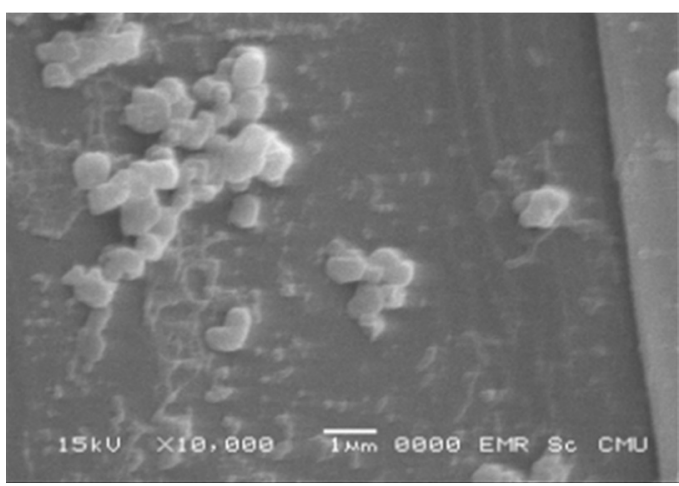

(a)

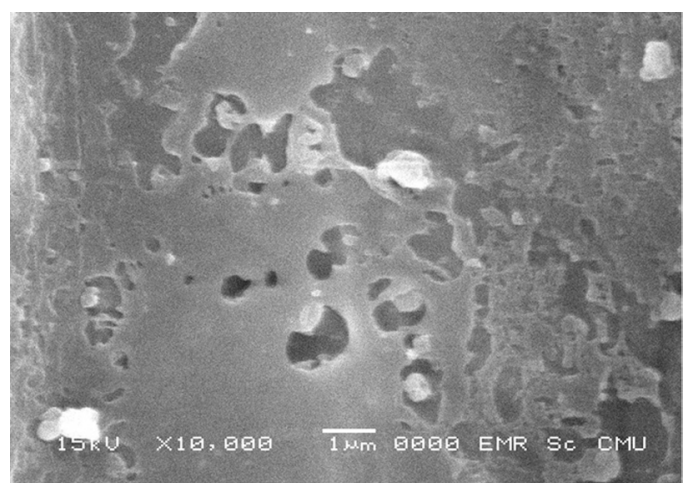

(b)

Figure 7. Phloem wall samples of sugarcane infected with white leaf disease not treated (a) and treated by solution plasma (b) at 10,000 times magnification.

\section{CONCLUSION}

The wire-to-wire and plasma jet systems were more effective than the gliding arc system for treating white leaf disease in sugarcane. While greater immersion times and power discharge reduced disease incidence the most, they also destroyed the phloem walls, reducing sugarcane growth. The most effective treatments, in terms of balancing plant growth and 
disease reduction, were the wire-to-wire system, with infected specimens immersed during discharge for $2 \mathrm{~min}$ with discharge repeated every $2 \mathrm{~min}$, for $120 \mathrm{~min}$ (EXP 13); and the plasma jet system, with infected specimens immersed during discharge for $30 \mathrm{~min}$ and then continuously immersed for $180 \mathrm{~min}$ (EXP 18). The wire-to-wire treatment yielded $50 \%$ diseasefree sugarcane specimens with $80 \%$ growth; the plasma jet system yielded fewer disease-free sugarcane specimens (40\%), but more growth (90\%). SEM results showed that the solution plasma treatments as a group reduced disease incidence by about one third compared to the controls.

\section{ACKNOWLEDGEMENTS}

The authors would like to thank the Center of Excellence on Agricultural Biotechnology, Faculty of Agriculture, Chiang Mai University; Lampang Agricultural Development and Research Center; Khon Kaen Crop Research Center; Agricultural Occupation Promotion and Development Center of the Department of Agricultural Extension, Kumphaeng Phet Province; and the Science and Technology Service Center, Faculty of Science, Chiang Mai University for their help with this study.

\section{REFERENCES}

Andreeva, N., Ishizaki, T. Baroch, P., and Saito, N., 2012. Rapid sterilization of Escherichia coli by solution plasma process. Japanese Journal of Applied Physics. 51(12R): 1-4. https://doi.org/ 10.1143/JJAP.51.126201

Chingsungnun, A., Jareansin, P., and Suttikam, W. 2016. Increasing wettability of Sericin silk power using on atmospheric pressure plasma jet treatment. Journal of Science and Technology. 35(1): 12-18.

El-Aragi, G. 2005. Gliding Arc Discharge (GAD) experiment. Plasma Physics and Nuclear Fusion Department. Nuclear Research Center, AEA, PO 13759.

Hanbunsong, Y. 2005. Molecular detection and transmission of sugarcane white leaf phytoplasma in leafhoppers. KKU Research Journal. 10(1): 13-21.

Junplang, O. 2012. Detection of Candidatus Phytoplasma spp. and Candidatus Liberibacter Asiaticus in Citrus showing greening systems from Bandmod district by nested PCR. Faculty of Agriculture Kamphaeng Saen, Kasetsart University.

Kalize, S. 2016. The Kalisz Lab, Ecology \& Evolutionary Biology Department, University of Tennessee.

Kim, S.C., Kim, J.W., Yoon, G.J., Nam, S.W., and Lee, S.Y. 2013. Antifungal effects of 3D scaffold type gelatin/Ag nanoparticles biocomposite prepared by solution plasma processing. Current Applied Physics. 13(1): S48-S53. https://doi.org/10.1016/j. cap.2013.01.035

Klinkong, S. 2015. Report of phytoplasma detection by Nested PCR (100 sample). Faculty of Agriculture Kamphaeng Saen, Kasetsart University. 
Ma, R., Wang, G., Tian, Y., Wang, K., Zhang, J., and Fang, J. 2015. Non-thermal plasmaactivated water inactivation of food-borne pathogen on fresh produce. Journal of Hazardous Materials. 300: 643-651. https://doi.org/10.1016/j.jhazmat.2015.07.061

Misra, N., Schluter, O., and Pullen, P. 2016. Cold plasma in food and agriculture fundamentals and applications. Academic Press, Massachusetts.

Om-Hashem, M., Neven, I., Sahar, A., and Shalaby, A.A. 2015. Molecular and electron microscope evidence for an association of phytoplasma with citrus witches broom disease. International Journal of Scientific \& Engineering Research. 6(6): 127-134.

Pagliari, L., Martini, M., Loschi, A., and Musetti, R. 2016. Looking inside phytoplasmainfected sieve elements: A combined microscopy approach using Arabidopsis thaliana as a model plant. Micron. 89: 87-97. https://doi.org/10.1016/j.micron.2016.07.007

Prasertsung, I., Damrongsakkul, S., and Saito, N. 2013. Degradation of $\beta$-chitosan by solution plasma process (SPP). Polymer Degradation and Stability. 98(10): 2089-2093. https:// doi.org/10.1016/j.polymdegradstab.2013.07.001

Roberston. 2017. Trilaminar membrane structure. Retrieved from https://www.slideshare. net/raiuniversity/bsc-micro-ii-microbial-physiology-unit-3-bacterial-permeation. Accessed on February 2017. 